\title{
Investigating organizational transformation in supply chains: A case study on B2B and Extranet impact
}

Organizations introduce e-business applications as a tool for seamless, streamlined and integrated supply chain operations. However, the findings underline that managers not only must recognize differences between individual e-business applications but also their impact upon their supply chains in order to avoid pushing one-size transformation efforts throughout their supply chains. This paper examines the impact of B2B and Extranet on one automotive supply chain and investigates its transformation context. A case study including a participant observation in an automotive supply chain has been used. The impact of B2B and Extranet has been evaluated based on eight dimensions of transformation. Consistent with the organizational transformation literature, the empirical results of transformation indicated that organizational transformation elements content, infrastructure, strategic intent are integral to transformation process in supply chains in terms of B2B and Extranet. However, same supply chain members may experience different patterns of impact based on each ebusiness application. The differences in this case study were observed in following organizational transformation dimensions; competencies, resources, challenges and strategic response. The present work is exploratory in nature. Further research is needed to validate and substantiate the findings in other supply chains.

Keywords Organisational transformation, supply chain, B2B, Extranet, automotive Industry

Paper type Research paper

\section{Introduction:}

E-business impact in supply chains can vary dependent on the context of organizations and industries. The e-business applications lead to reports on cost savings, performance and collaboration increases in supply chains (Nyaga et al., 2010; Weingarten et al. 2010). Especially, the impact of e-business technologies is 
prevalent in automotive industry (Ireland, 1999; Bagchi and Skjott-Larsen, 2005; Weingarten et al. 2010). For example, BMWs' case, it spent $55 \$$ million on its European wide online procurement system, resulting with a decreased order delivery times of 20 days on average (Holweg and Pil, 2001). Similarly, Holweg and Miemczyk (2003) acknowledged if cars were built-to-order, cost savings would amount to 500-1500 US\$ per vehicle across all global markets. Such a potential of e-business applications introduced cost-savings in automotive industry may not be too surprising considering that as many as 453,000 product data exchange occurs each year throughout the automotive supply chains (Brunnemeier and Martin, 2002). This is especially important for an industry where profits are increasingly coming under pressure with maturity of the margins and financial restraints (Doherty and Locke, 2001). Despite the ebusiness impact may be beneficial and necessary for the automotive industry; nevertheless it isn't without any challenges. It is interesting that there are only a few systematic studies on e-business applications and its impact upon supply chains' and its transformation. Despite technological enhancements over the years, challenges organizations facing remained almost identical. Similar questions on how organizations should analyze transformational impact of ebusiness applications (Fahey et al. 2001), as well as to what extent e-business applications affected the organisations (Gale and Abraham, 2005), and how to assess such transformation (Abraham and Junglas, 2011). In the operations management (OM) literature researchers such as Rosenzweig, (2011), Taylor and Taylor (2009) have emphasized the lack of organisational context as well as multidisciplinary research, with a particular emphasis on "information technology" and "organisational theory" (Donk, 2007, Banker et al., 2006; Heim and Peng, 2010). Taylor and Taylor (2009:1325) described this limitation in the field as an opportunity for OM researchers “...to draw upon relevant theories from adjacent disciplines such as organisational studies and information systems, not simply to offer alternative insights but to enrich and even challenge the underlying philosophical assumptions". The absence of multidisciplinary research across operations management $(\mathrm{OM})$, organizational transformation (OT) and Information Technology (IT) can be observed in the literature. 
A study conducted by Mohdzain and Ward (2007) investigated the multinational companies and their subsidiaries on the impact of information technologies; another study on multinational companies undertaken by Finnegan and Longaigh (2002) looked at operational and environmental factors effecting the information systems related decisions. One of the earliest research investigating the impact of e-business applications that entailed 181 respondents from diverse range of industries was conducted by Lancioni et al. (2000). McCormack and Lockamy (2001) as well as Lancioni et al. (2000) agreed that an industry specific comparison would be of particular interest to determine industry-specific implications of e-business applications. Based on the above summary, the following observations are identified: (1) Most of the studies focus on the impact of stand-alone application on supply chains; (2) Studies on organisational transformation within supply chains are limited in their multidisciplinary effort. (3)It is still unclear whether what the supply chains are experiencing through the e-business technologies can be considered as organisational transformation.

The following part will explore organizational transformation context and identify eight structuring themes of transformation, followed by the introduction of the case study and findings.

\section{Exploring Organisational Transformation}

In the literature organisational transformation is analogues to second-order change (Levy, 1986), second-generation organisational development (Porras and Silvers, 1991), strategic change (Dunphy and Griffiths, 1998). Similar to Cady and Hardalupas (1999) in this study the term "transformation" will be used which describes a shift in the supply chain from its "old state of things to the new state of things" (French and Bell, 1999:2) necessitating deep, broad and fundamental change in operational paradigms, practices in the organisation (Blumenthal and Haspeslagh, 2002; Vollmann, 1996; Beers, 1997; Cady and Hardalupas, 1999). Transformation is not just about changing the company through business process reengineering or reducing the cost; it is rather introduction of new ideas and beliefs, which drives the organisation (Prahalad \& Oosterveld, 1999). Transformation can empirically be observed as a difference in form, quality, or 
state over time within the organizations. Research in the area of transformation mainly concentrated on content specific questions "why and when organisations transformed", "to which extent they transformed", and "whether transformation has been beneficial at all for the organisations". In trying to understand the transformation, Rockart and Scott-Morton (1984) drew attention towards the interlinkage between strategy, processes, individuals' roles and organisational culture in understanding transformation. Later in 1991 Scott-Morton included a parallel notion that organisations balance four elements; tasks, structure, people and technology. Similarly, five years later Vollmann et al. (1996), whilst discussing the transformative imperative with academics and industry, extended transformation around eight structuring themes; strategic intent, competencies, processes, resources, output, strategic response, challenges, and learning capacity (Vollmann, 1996; Farhoomad and Wigand, 2003). The structuring themes were an organic follow-up from elements mentioned earlier, but extended with new themes such as challenges, learning capacity and strategic output. Todays research moving from earlier works still includes the discussion on transformation, which revolves around similar themes (Abraham and Jungs, 2011; Igira and Aanestad, 2009). Factors from the literature review singly or in combination define the constructs that are prevalent when undergoing transformation. Two sources in addition to transformation constructs by Vollmann (1996) and Scott-Morton (1992) have been added, namely the stimuli and process scope. Although these are essentially subset of transformation, we have chosen to highlight these as they are viewed particularly important when undergoing transformation and indicate high variance between organisations.

1. Strategic Intent: The strategic intent "encompasses the way that a particular firm chooses to compete, where it sees itself going over the long run... in the light of industry context, external- and internal discontinuities, and the expectations of customers and stakeholders" (Vollmann et al. 1996:95). Thus, the strategic intent creates a fundamental shift, which drives objectives and measures as well as actions and rewards. The transformation journey can start by identifying the behaviors that get rewarded, for example, assigning role models, or to list the things that the 
company will measure (Vollmann, 1996:53-54). The gap between the strategic intent and current competencies needs to be overcome within the transformation agenda (Vollmann, 1996; Scott-Morton,1991).

2. Competencies: Transformation of competencies is a complex process, the gap between the desired and current existent competencies are what an organisation needs to identify, at three levels; "distinctive competencies" which cannot easily be copied, "essential competencies" common for immediate competitors, but necessary, and "routine competencies" which is common across organisations or it can be an activity which is more profitably outsourced (Vollmann, 1996:56). Developing new competencies and leveraging existing competencies are the drivers of transformation (Vollmann, 1996; King, 1997). Similarly, a study conducted by Francis et al. (2003) suggest that a different set of new competencies needs to be acquired for the transformation agenda. As Fine (1998 as cited in Chandrashekar and Schary, 1999) puts it "... the greatest rewards go to the companies that can anticipate, time after time, which [competencies] are worth investing in and which should be outsourced; which should be discarded; which shall be the levers of value chain control and which will be controlled by others".

3. Processes: Transformation may require a change in organisations processes (Bak, 2012). Through changes in processes new organisational structures may become visible. In transformation, the processes may require the set-up of ad-hoc teams as a way to get jobs done (Scott- Morton, 1991, Bak, 2012; Junglas, 2011). As resources, project teams are key for transformation-which will almost always include changes to the formal and informal organisation. Project teams consolidate new ideas, manage pilots and full implementation and coordinate efforts between parts of the organisation (Butler, 2000). Project teams themselves shatter existing organisational forms, and their increasing use is recognition in an enterprise of the need for continual renewal. Those who lead the teams, as well as those who serve on them, need to see these efforts not as a 
secondary part of their job, but as the way that the enterprise is going to survive (Vollmann, 1996:112). Defining the end state to be achieved by transformation is easier than determining how to achieve such a state quickly (Vollmann, 1996:110). Implementation is the "how" of responding to the discontinuities, and the changes in customer expectations. It includes recognizing and dealing with constraints, articulating the desired paradigm shift, and following this up with a consistent, integrated set of actions and changes with underlying processes and resources (Vollmann, 1996:112).

4. Resources: There are three fundamental resources of a company; its people, technology and information. Transforming people: “... one often needs to change skills, actions, and behavior-and the fundamental paradigms for seeing the enterprise: what it needs to achieve transformation" (Vollmann, 1996:66). Technology; This will lead to greater shrinkage of time and distance effects, greater interconnectedness and better organisational memory with greater capture of organisation rules (Scott-Morton, 1991:21). Changing the way people work can be extremely threatening and therefore takes a great deal of investment. There must be investment in new skills, in ownership of transformation process. The members might be reluctant to invest in forming partnerships and integrating business processes if they perceive either their role or share of gains in the supply chain is diminishing or trading parties will become eventually competitors (Au and Ho, 2002). In addition to this organisations may possess different subcultures (ibid). Current culture directs and constrains transformation efforts. Scott Morton (1991) and Junglas (2011) comment that the cultural issues related to people within the organisations can be critical in transformation process.

5. The strategic response: According to Vollmann (1996:74), an enterprise can be seen as the sum total of its responses and actions. "The actions view of the enterprise transformation necessitates a critical review of all action 
programs and their match with the transformation objectives. If, for example, transformation is started as a top-down paradigm shift based on customer focus and with a newly defined strategic intent, one needs to examine current actions carefully to see which ones best match the new objectives, which are counterproductive, and how a revised set of action programs should be prioritized (Vollmann, 1996:75). Conversely, sometimes transformations are driven by the action programs rather than asking it, whether this action is consistent with the other facets of transformation". “

6. The challenges: Challenges can be split into two forces, the internal and external according to Cummins and Huse (1995), both environmental and internal disruptions may trigger transformations.“... enterprise transformation is seen as occurring in response to forces and constraintsboth internal to the enterprise and external to it (Vollmann, 1996:77). External challenges may encompass the competitive, social and political forces as well as the technological thrusts that affect all players in the industry including the expectations of customers and stakeholders. Stakeholder can be the employees, the unions, the local communities, the government or pressure groups. Changes in expectations can influence the strategy, so for example the customer expectations for a better service, new product features, new support linkages. Moodley (2002) has also identified that the challenges are wide ranging in the automotive industry when trying to transform through the e-business applications, the challenges were varying such as pressing company, senior management priorities, lack of e-business skills, senior management support.

7. The learning capacity: Transformation requires a firm to learn faster than its competitors. According to Kotnour (2001) learning is the creation, share and application of knowledge. The land can be counterproductive to newly desired end objectives, thus transformation, hence it is important that employees will have new processes; learning needs of the e-business tools introduced (Bak, 2012). In addition Benjamin and Levinson (1993) suggest 
that IT-enabled change processes are different from more general change processes in that they create unique issues for managers. Therefore, the managers are expected to know how to integrate the technology, business processes, and organisation in order to achieve the goals they expect with the technology. Learning can be also a response to external or internal stimuli (Levitt and March 1988; Miner 1992). Additional training is needed to ensure effective use of the tools, and to cope with the blurring of boundaries between job categories and tasks, management processes (Scott-Morton, 1991).

8. Output: The resultant service and/or product may be also impacted by the transformation itself. The nature of the service or how the product has been delivered may experience also a transformation in this sense (Junglas, 2011). Bak (2012) when investigated into e-business enabled organizational transformation agenda observed that the output might vary based on the application and its impact to final product and/or service.

9. Stimuli: Despite the presence of similar transformation elements, there is an ambiguity concerning the time frame of transformations. The reported time frame varies between 1 to 15 years, meaning that sometimes a oncefor-all effort or an effort lasting through several stages of a supply chains life is needed. For example, Hall et al. (1993) and Anderson et al. (1985) report transformation as a series of waves lasting between 5-10 years, whereas Kotter (1995) report in a transformation effort of 1-2 years. Therefore, an assumption can be made that the differences in the speed of transformation might rely on the nature and the scope of transformation that organisations are undergoing. Another ambiguity exists in the discussions on the stimuli, the reasoning behind the transformation. In the literature the stimuli for transformation can be a result of a responsive/ flexible stimuli, where supply chains decide to transform after scanning their competitors in order to compete. An anticipatory/ forecasting stimuli whereby supply chains analyze and anticipate the future challenges that could lead to a threat, and take steps accordingly to respond to these future 
threats or a proactive/ causing starting the transformation effort before it is needed or even envisaged. Francis et al. (2003) agrees that there might be several reasons of transformation, therefore, the transformation imperative can result from opportunity to a result of a threat. What they have in common is that the transformation agenda leads companies in areas where the company has much to learn and to learn it quickly enough (Hamel, 2001).

Having defined the structuring themes involving organizational transformation, the next section describes, how the research agenda and the case study was set to explore the phenomena and the reasons behind the methods utilized.

\section{Setting research design and method}

(1) Case study: The case study method was selected as an inductive research strategy where focus is on contemporary phenomena with real-life context (Siggelkow, 2007). A single case study setting has been specifically selected to "close in" on real-life situation to allow the researcher the opportunity "to test views directly in relation to phenomena as they unfold in practice" (Flyvbjerg, 2006:235). In this study, the case study approach provided the profundity looked for, such as gaining an understanding of transformation process. The nature of transformation and involvement of participant observation makes it practically challenging to elaborate on an extensive number of case studies, thus limiting the researchers ability to a transformation setting within limited time (Van de Ven and Huber, 1990). Typically, priority is given here to the nature of observation, requiring the immersion of the researcher into the context. Hence, the case study entailed participant observation involving, meeting minutes, diary, and interviews', archival documents, organisations records, which provided additional information about the topic under study. The participant observation allows here a unique opportunity for data collection, which presents a source for full access to the phenomenon (Bryman, 1989; Yin, 1994). Charms (2000) also recognizes that the knowledge created by the viewer and the viewed aims towards interpretive understanding of subjects' meanings. The transformation impact of 
B2B and Extranet were coded separately. Although the subcategories seemed to entail the similar labels, the transformation context of the codes was different in both cases (B2B and Extranet). The triangulation across various techniques of data collection proved to be particularly beneficial as it provided multiple perspectives on the phenomenon under study, and supplied more information on emerging concepts, and allowed for cross-checking.

(2) Data analysis: A priori conceptual framework has been developed based on the literature on organizational transformation. Our case study was based on the eight structuring themes as well as a descriptive case study. Pattern matching and explanation building were used when analyzing case data (Trochim, 1989; Yin, 2009). The case study, hence entailed a comparison between empirical patterns and a priori framework. The a priori framework is used also as a tool to enhance internal validity (Yin, 2009).

(3) The Case Background: The case organization consisted of approximately 550 employees. The data for this study was obtained from a European automotive supply chain. The automotive industry is one of the most important manufacturing industries in the world with Europe contributing 31 per cent of global production (Wiengarten, 2010). Focusing on research on a single industry assists in the control of extraneous industry factors that could confound the analysis and its findings (Zhu, 2004).

- Introducing Extranet: Extranet facilitated information sharing between supply chain members. The use of the Extranet would allow the supply chain members to publish the details of the products, acquire after sales services details, and gain information across the supply chain from the suppliers to distributors. This again enabled the members of the supply chain to retrieve updated information on products and changes, processes, research results, tests, and other processes from the proximity of their home or workplace. In addition to the time and information acquisition advantages, supply chain members could integrate with the related business unit. There were three main justifications for using an Extranet; 
first it would leverage existing investments through real-time information sharing and access (online documentation and information database access), secondly it would standardise processes, hence enable reduction in operation time. Thirdly, customised supply chain and individual members needs which would be available and accessible on a 24/7 basis. Furthermore, it would allow connection of multiple and diverse organizations behind online virtual firewalls, extending the Intranet that includes strategic partners, suppliers, distributors, contracts and others that operate within the physical walls of organizations supply chain. Extending supply chain boundaries enables the coordination as well as prevents illegal access in a secure environment. The members of the supply chain have been provided with passwords to attain an access the Extranet. This shift has implications on the supply chain members but is also believed that the usage of this e-business application will increase the efficiency and add significant value to the employees' work.

- Introducing B2B: The senior management drove the B2B effort. Compared to Extranet supply chain members were reluctant of the B2B introduction, and was questioning why " [B2B] was necessary and whether it will add any value to the existing processes, products or service". Especially in the supplier-distributor network meeting there were still discussions on financial, infrastructural and value added challenges. The senior management believed that the e-business application would create a better relationship and improved supply chain integration. At initial phase research was conducted on the requirements, tools and techniques and options on the software. However, the departments and the distributors found themselves rushed into internally created deadlines whereby a research project was commissioned to determine specifically what this B2B offering should comprise. After the preliminary screening of providers only one company remained, which was a close partner on several other projects. Based on feedback and ideas, including information architecture, and possible layouts, design, portfolio of potential services and content was provided. The initial discussions and meetings allowed knowing that what 
was being done was something in line with what the distributors wanted, and the partners needed.

The technical requirements were driven by the software company and IT department, wherein the distributor, business partners and the senior management provided the initial input for the functional requirements, so that the various internal systems and Web services which needed to be exposed and integrated were set forth. From the beginning it was apparent that this was a technically complex project and hence a framework was created. Before the operationalisation of the system it needed to be tested in the development phase (in a fully working environment). Again, the pilot tests indicated that there were severe technological, organisational and functional problem areas and that a transformation was necessary. The internal pilot test indicated that it needed changes if they wanted to go ahead. This period allowed pilot testing it under realworld conditions. There were still few technical and organisational problems before going online.

\section{Results}

The automotive supply chain introduced two separate e-business applications, the B2B (Business-to-Business) and Extranet. The presence of two e-business applications proved to be beneficial for the researcher to detect similarities and to compare differences between them and the impact on organisation. Before the operationalisation the system needed a pilot in the development phase in working environment. Again, the pilots indicated that there were severe technological, organisational and functional issues and changes were necessary. The internal pilot test indicated that it needed transformation of processes if they wanted to go into full launch without causing mayhem. This period allowed testing these processes under real-world conditions. The project team was confused and concerned about the instability and issues that needed to be tackled. There were still few problems before going online. This section will look into the transformation elements and evaluate whether the e- business applications such as B2B and Extranet. The impact needs to be evaluated where transformation has its impact in categories. As formerly stated, the categories derived initially from the 
literature in terms of a matrix, within time some categories have merged with other categories, and subcategories merged. The first category under the investigation was the stimuli.

(1) Stimuli: Both applications were introduced based on responsive stimuli, with B2B having also a proactive reasoning behind it. Similarly, when Au and Ho (2002) investigated the B2B model for enabling supply chain management (SCM) on clothing supply chain, they observed that B2B effort was driven by proactive stimuli. This is inline with Teo et al. (1995) findings, which reported that organisations plan proactively to implement the e-business application, based on the basis of improvement rather than to respond to external pressures. The transformation showed a responsive/flexible reasoning whereby the organization scanned the competition and applied what others did in the same market. One interviewer noting, “...of course we need to catch the bandwagon but this is not always what we want to do, the application of this system was rather senior management's decision. They believed it would be better to start now, rather than later...” However in the case B2B showed rather a combination of both, mainly a responsive and proactive reasoning. Although there was agreement on that it would bring improvements there were still questions on the value added through the system.

"We might have been even late in setting up the Extranet...although the suppliers and distributors where quiet happy with the current status...making them to understand the importance of the platform will become easy once the results of the existing studies on efficiency and less paperwork will come out. With Extranet, the resistance although was less when compared to B2B”

This finding can be linked to Francis et al. (2003) transformation can result from several reasons. When looked into the Extranet, there was consensus in the statements on responsive reasoning. It is interesting to see to different point of views in terms of the different applications within the case,

(2) Formulation Scope: In the literature transformation could be defined in a revolutionary or in evolutionary manner lasting from 1 to 15 years. The slight disagreement even opened doors to new discussion platforms between academics, such 
as in the special issue discussing "B2B E-Commerce Revisited: Revolution or Evolution?” (Electronic Markets, 2002). In this research in order to evaluate the formulation scope of the transformation the participants have been asked to define the formulation scope of the change. There have been ranging answers from revolutionary to evolutionary transformation. One interviewee noted that:

“The business unit defined this change as transformational as it justified the following points according to a member of the project team; it is transformational, because we have a complete new system....[It] has a direct effect on how we do the things around here... including structural changes ... training of the employees to use the system...new job definitions and division of tasks... some see that as an extra workload but some see that as a necessity to compete....”.

One distributor commented on the new system welcomingly, showing the change extent "[it] will effect the salesman, when he goes to the customer he would just need his laptop and to connect into the network to do his presentation or to answer any sort of question, and to get our full support... paperless environment... no catalogues... technical sheets...price list...just a click ... you have all the information you need to have” . When asked to the consultant it seemed like that he sees it evolutionary from his/her own perspective, but still believes that the change is radical when faced in this organisation.

"I would see any new system as a part of the evolution that we are in, rather than revolution. However, I still believe that the impact of the system will be radical in this organisation, wherein everything seems to be bound to several decision making instances”

Although one could argue that evolutionary change is part of the revolutionary change like the former interviewee, the case study indicated differences when both applications were compared. The B2B compared to Extranet, the transformation seems to be rather evolutionary. "Extranet, seemed as a logical extension of our Intranet wherein we could log in to the Extranet and see the information we needed and vice versa, and the information was related to the divisions and to the supplier and distributor. Each access was restricted at some level... [which] gave the participants the possibility to use a new platform". The view that the transformation was evolutionary rather revolutionary 
stems from the understanding of similar platforms, which was, build upon. Whereas in the B2B case the system was completely new, and there were limited reference to it between the supply chain members.

(3) Process Scope: Processes were defined as “a set of logically related tasks performed to achieve a defined business outcome” (Vollmann, 1996:60). The definition identifies two important processes in this research characteristic such as the interdependency of processes and impact on the outcome. In this research the process scope category entailed the processes crossing the individual boundaries of internal and external supply chain members. When looked within the internal supply chain, the cross-functional process scope, cooperation between the individual departments is related to this topic. [For Extranet] a matrix was needed, which described the process responsibilities. The workflow administrator asked the participants to create a matrix of responsibilities stating different tasks listed and matched with a responsible employee for the task. Some voices welcomed the well-organized process scope, whereas some disliked the fact that there were new processes with new tasks "good news, now we have additional workload"... The employees were advised to choose a chief editor for controlling and decision-making, but nobody seemed willing to take the control function....one commented "let's decide this later and see and wait how the system will work...until than Mr. ... will take the responsibility".

The transformation of workflow created confusion and resistance as to the understanding of the workflow was not given alongside the announcement and the training. Similarly McIvor et al. (2003) found that within supply chains different functions or departments often had incompatible systems and objectives. Workflow and the transformation of the workflow is to the extent which job responsibilities are expressed in written rules and regulations and employees are evaluated based on the written procedures. A formalized organization has a set of written tools and tools to develop and handle the decision making in business processes (Marshall, 1992). The Extranet has created in certain departments' additional workload and processes, causing disagreements. One of the interviewee's underlines this impact also.

“After the competent use of Intranet, Extranet was a logical extension for our external network...It was not very welcomed as it entailed additional processes 
and tasks to complete...[Extranet] however seemed beneficial, when we recognise how much time we saved with the Intranet, this definitely will save us time too...maybe we do not have to deal with enquiries like updates on product information and specification...finding an address of the distributor or supplier...All our external network was considered in Extranet”

Hence cross-functionality of the process coupled with employees can easily collaborate in remote locations (Grover, et al., 1995). The same case was also with B2B, but creating more complexity at the same time, because it did encompass structural and organisational transformation requiring substantial investment and training. Both Extranet and B2B required multi-stage process scope meaning that it took place in several stages and in different departments. Through a single strategy was not prevalent among the supply chain participants, the wide variety of results had common characteristics.

(4) Strategic Intent: The strategic intent derives from the organisations vision and mission and needs to fulfil its strategic response (Venkatraman, 1994; Vollmann, 1996; Scott-Morton 1991). Managers would need to identify the impact on e-business applications on their organisations as part of long-term corporate strategy and vision, as well as how the corporate strategy should drive the Internet applications (Glavin \& Radtke, 1997; Palmer, 1997:22). The mission statement should specify the organisations reason for being in business, "the goal in being on-line, and the method of reaching that goal” (Levinson\& Rubin, 1996:4). The analysis of the case study showed that the strategic intent has been also transformed in B2B due to following reasons:

"We used the old system over 10 years however it does not respond to our needs anymore...The hardware and user support was given by the division, it was an isolated world....We were depending on pure internal service-solutions, with limited functions, hence the discrepancy between the vision and the market needs were unavoidable...Speed became as success deciding factor... [Especially] requiring early action for European wide tender obligation, as well as the pressure of increasing purchasing power of the procurer. Supply chain care of customer relations with total care from marketing through...factory to service...widened 
service offer”

Compared to B2B, Extranet transformation did have limited impact upon the strategic intent. It was seen as a logical extension of the Intranet, which allowed the information sharing between the suppliers, distributors and the OEM. "I do not believe that Extranet did have an impact on the strategy...Extranet is just a dot within the whole picture...an important part but not that important again” This is an interesting finding the strategic intent that drives the mission and vision seems to be impacting at different levels in terms of both applications. In B2B case there was indication that strategic intent was driven by the stimuli, which also impacted the strategic intent.

(5) Competencies: Competencies enable the transformation (Venkatraman, 1994; Vollmann, 1996; Scott-Morton 1991) which can be depicted “distinctive”, “essential”, and "routine competency" (Vollmann, 1996:56). In the B2B case we can see that the transformation was in need of distinctive capacity in leveraging existing capabilities and in acquiring new capabilities, which was also reflected by one interviewee "the different tasks have been listed and allocated with the responding competency ... employees are assigned for the tasks, however some tasks are noted with a question mark...”. The consideration was focused on, which capabilities are worth investing in and which should be outsourced; which should be discarded; which shall be the levers of value chain control and which will be controlled by others (Chandereshkar and Scary). Or whether leveraging and improving towards the new distinctive competencies can arrange this. "The leveraging of the existing competencies in a changing environment doesn't allow employing additional people for this project and taking new people into the project would create additional problem.” The IT department answered this comment by saying that they don't have enough people and some problems are also rather software based than the IT department could solve the problems. One of the IT team which was positioned in the project team said that there is a difference between software and IT "It cannot go further in this way, I cannot try to solve all IT problems, I do understand from computers but I am not an IS person".

However as stated in above statement in some cases the employees were not willing to transform and in other could not due to time limitations. This is inline with the findings of Vollmann (1996) and King (1997) wherein the transformation of competencies is a 
complex process, what competencies are required and which are existent and which of them needs to be transformed requires an analysis. Developing new competencies and leveraging existing competencies are the drivers of transformation. The significance of Extranet can be also linked that to the external partners being mostly SMEs requiring technical competencies. Especially this has been the case with the suppliers and distributors, who were unwilling to invest in the competencies and did not think that the competencies were relavant to their business. Similarly, Boyer and Olson (2002) found a low level of adoption of Internet technologies among SME`s.

(6) Resources: There are three fundamental resources of a company; its people, technology and information (Vollmann, 1996:64, Scott-Morton 1991). Transforming people: “... one often needs to change skills, actions, and behaviour-and the fundamental paradigms for seeing the enterprise: what it needs to achieve transformation” (Vollmann, 1996:66). Changing the way people work can be extremely threatening and therefore takes a great deal of investment. There must be investment in new skills, in ownership of the change process. These investments are required throughout the organisation as management itself is part of the required change (ScottMorton, 1991:21). McIvor et al. (2003) suppliers are expected to embrace collaborative relationship after many years of operating in a system which trust was the last thing they expected. Quayle (2003) in a study of SMEs in the UK that new e-business technology was of least importance (both 2.5/5.0). The B2B might be explained with the fact that in well-organized supply chains, the synergy is created through the allocation of resources. Some supply chains have their own software development department with internal consultants, and online support or even a division dedicated solely to the transformation or development.

(7) Learning capacity: Transformation requires a firm to learn faster than its competitors, as the experience gained results through learning new measures, when in fact there is also a need to eliminate some existing metrics. Unlearning necessitates elimination of measures as “... elimination of measures is important for several reasons. First, some established measures can be counterproductive to newly desired end objectives. Second, a measure that is important at one time may be less so later because a series of actions has taken place to solve the problem the measure was set to evaluate" (Vollmann, 1996:84). Additional training will be needed to ensure effective use of the 
tools, and more education will be required to allow individuals to cope with the blurring of boundaries between job categories and tasks, management processes.

In the case study active education and training programmes were found in two embedded cases. Training people was necessary in order to facilitate change throughout the organisation. The goal in training was also to encourage employees to take ownership. By changing the structure of the working environment employees realised that there was "no going back" to the old way of doing business. Kwon and Zmund (1987) findings were similar in which they identified the barriers to information sharing as resistance of change and learning capacity skills. In which “....learning creates the competencies necessary to enable the strategic response to achieve the strategic intent to meet and exceed the challenges” (Vollmann, 1996:48). Transformation leads companies into areas where the company has much to learn and to learn it quickly enough (Hamel, 2001). Today technological change still drives the need for training, however due to the increased technological changes, the disruptions that took longer time to play out, now only take a matter of months (Scott Morton, 1991; Champy, 1996). The findings were similar to Huang and Mak (1999) wherein the extranet technology was not only embraced within the MNC but also required the training of the key suppliers.

(8) Output: One of the areas that have been not mentioned in terms of the e-business impact has been the output. In both cases B2B and the Extranet had no impact on the final product. As mentioned earlier output can be described as a bundle of goods and services that enterprise produces. The impact of the individual applications on the product automotive seems to be not relevant in this case, but it does have an impact on the associated services. For example after sales department changed the way of service interaction; it improved the communication between the parties, although it did not have an impact on the product itself. Whereas Extranet had no impact on the product; it influenced the distributor, supplier and the business triangle whereby they had an accessible platform of 24/7 with the necessary data sets and connections for information.

(9) Challenges: Challenges were split into two categories environmental and internal. Vollmann (1996) used the term internal, for forces and constraints that are unique for firms and external, which impacts all players in a particular industry. In this study 
However in this case the challenges were relevant to individual applications, for example B2B case the challenges were related to internal and external whereas in the extranet case the challenges evolved internally. It is the difficult to challenge the "way we do things around here”. It has direct constrains on transformation. Changes in subunit missions, plant charters, and organisational forms all represent potential configuration changes. Coordination refers to management and control within the business system itself. Transformation normally requires new flows of information cash and materials as well as new sets of managerial responsibilities. Configuration relates to both organisational designs and relationships, and to physical or geographical distributions of people, capital, and equipment.

(9) Strategic Response: According to Vollmann (1996), actions necessitate a critical review in the transformation context. In line with Vollmann's definition in the case of both application different set of strategic responses were reported. The actions taken in B2B were the assessment of the individual departments' needs wherein employees were consulted about the impact of this particular application and the internal resistance and its underlying reasons were discussed. The project team was seen as a change agent assessing the needs. The communication gap between IT personnel and the users of B2B needed the creation of new action points.

When compared to the Extranet the strategic response showed a different profile. Through the Extranet the actions impacted was the individual needs were assessed and implemented within the systems boundaries. However in this case, the system was similar to Intranet; hence partners were informed about the possible impacts and actions that need to be taken (short-long term basis). The project team members were able to apply the action points as the internal house capabilities had blueprints resulting from the Intranet issues; these were adapted to the needs of extranet environment, so that the impact can be evaluated earlier. Similarly Grover and Saeed (2004) when looking into the boom of the Internet companies find out that most Internet based companies are strategic intent driven even though the intent might differ in terms of the individual firm. Complementary to findings of Wilcocks and Sauer (2004) in their work that strategic intent drives the establishment of an IT infrastructure, similarly the resulted here indicated that the e-business applications differ in choices of e-business applications and each application require different responses in terms of strategic intent. 
The post hoc test also identified the individual applications and their differences. This can be also related to the implementation of the planning process rather than impact of the process as stated by Kaefer and Bondoly (2004) when measuring the of organizational constraints on the success of e-business efforts on capability, they found that it can be influenced by the number of participants engaged in business contracts, and the basic willingness.

\section{Conclusion, managerial and theoretical implications}

\subsection{Conclusion}

In this paper, transformation elements are explored and their impact were considered based on individual e-business applications: extranet and B2B. According to Moodley (1999) it is important to know the main areas of impact, so that the necessary changes can be made.This study advances the theory-building effort in the area of transformation and supply chain management. The individual e-business applications were different when compared to each other in its characteristics, including strategic intent, process, competencies, and learning capacity. These outcomes of transformation characteristics should support acceleration of the transformation process. The initial research question that one asked was if the literature is underlying a transformation through e-business applications, could we find empirical evidence on as a transformation undergoing among the business units of supply chains. Based on the literature on transformation, it was important for companies to perceive the transformation as positive for the organisation in order to be successful (Ross and Beath, 2002). The transformation must be supported by vision, management support, and training (Vollmann, 1996). Hence, it was important that an organisation needed to understand the interconnection between the applications and the necessary change or transformation needed. The transformation elements, especially the challenges, and the impact of e-business technologies were difficult to measure for the applications. However other elements, such as; strategic intent and learning capacity pertain the importance on transformation process. During the participant observation while the participants needs have also defined the transformation the researcher observed many participants expressing confusion and pressure when dealing with the items requiring a fundamental shift in their behaviours. Based on the results of this study the individual 
applications and business units received the message that the transformation perceived at different elements. Consistent with organizational transformation literature, the empirical results of transformation indicated that organizational transformation elements content, infrastructure, strategic intent are integral to transformation process in supply chains in terms of B2B and Extranet. However, same supply chain members may experience different patterns of impact based on each ebusiness application. The differences in this case study were observed in following organizational transformation dimensions; competencies, resources, challenges and strategic response.

\subsection{Implications for practice}

This study advises managers that before jumping on the transformation bandwagon, they should assess the transformation needed. If their supply chain relations were such that they do need to distribute with supply chain members, then they would need to consider their needs as well, which would require investing in elaborate external applications. Firms are also advised to asses the need for internal as well as external consultancy needs and then decide whether the inclusion of such services inherently will enable their transformation process, or, build the requisite on top of their existing burden. Additionally, it will be prudent for managers to asses the challenges involved in transformation in a supply chain context and carefully weigh whether they should introduce an incremental or radical change process or phase it. The key lesson for managers here is that many of the transformation will incorporate other members of supply chain, who may lack the commitment, resources, capacity, and capabilities to enforce a transformation. In a similar vein, managers are advised

\subsection{Implications for theory}

This study has theoretical implications in the following research agendas; first, a research that integrates theories of transformation and Internet-enabled supply chain management at the supply chain level has been carried out providing an in-depth study of two e-business applications. The research specifies the drivers of supply chain transformation and their impact on its management. This study hence advanced the theory-building effort in the area of transformation and supply chain management. Second, this study attempted to extend Vollmann`s (1996) work on transformation in 
supply chain management context. Vollmann argues that transformation is characterized by its elements and transformation, this study also enhanced the understanding of the variations of transformations across business units of supply chains and the ability to manage the synergies. Third, the research incorporated the concept of transformation as a part of supply chain concept while many organisations have been shifting supply chain activities online, this study supplies empirical evidence on the transformation. Finally, the research is conducted in automotive industry context. Therefore, it identifies how organisations manage the transformation in automotive industry.

These suggestions for future research are discussed for improving this study and transformation literature in supply chain context. Three areas are presented for improvement in this study some of the most important are: One way of enhancing the research might be to take advantage of the findings in a larger set of applications, which could examine whether these findings are exemplary for a larger sample groups. Presenting data or management discussion on other factors that are likely to impact the transformation and reporting these could increases readers confidence that the observed accrual pattern is attributable to bonus plan incentives. For example, is there a strong link between internet- enabled tools and the impact on infrastructure (which presumably is tied to specific tools). This study provides important insight into current impact on automotive supply chain. A further investigation could also explore more in detail the individual technologies to determine their impact in detail.

\section{References}

Abraham, C., and Junglas, I. (2011). "From cacophony to harmony: A case study about the IS implementation process as an opportunity for organizational transformation at Sentara Healthcare", Journal of Strategic Information Systems 20, pp.177-197.

Baum, J. A. C. (1999). Organizational ecology. In Studying Organization, S. R. Clegg \& C. Hardy (Eds.), SAGE, London. 
Blumenthal, D., 2009. Stimulating the adoption of health information technology. New England Journal of Medicine 360 (15), 1477-1479.

Burn, J. and Ash,C. (2005). A dynamic model of e-business strategies for ERP enabled organisations. Industrial Management and Data Systems. Vol.105(8), pp.1084-1095

Cady SH and Hardalupas L (1999) A lexicon for organizational change: Examining the use of language in popular, practitioner, and scholar periodicals, The Journal of Applied Business Research, 15(4): 81-94.

Carr, A.S. and Kaynak, H. (2007). Communication methods, information sharing, supplier development and performance; an empirical study of their relationship. International Journal of Operations and Production Management. Vol.27, No. 4, pp.346-370

Kathy, Charmaz. "Grounded Theory Methodology: Objectivist and Constructivist Qualitative Methods,[w:] NK Denzin, Y. Lincoln (eds.), Handbook of Qualitative Research." (2000): 509-535.

Champy, J. (1996)."Reengineering Management-Managing the change to the Reengineered Corporation."

Chandrasekhar, A. and Schary, P.B. (1999) "Toward the Virtual Supply chain: The Convergence of IT and Organization", International Journal of Logistics Management, 10 (2), pp.27 - 40

Cummings T.G., Huse, E. F., (1985) "Organizational Development and Change" West Publications. 
Doherty, N.F., Champion D. and Wang, L. (2010), "An holistic approach to understanding the changing nature of organisational structure" Information Technology \& People Vol. 23 No. 2, pp. 116-135

Donk, D.P.V. (2007) "Challenges in relating supply chain management and information and communication technology: An introduction", International Journal of Operations \& Production Management, Vol. 28 Iss: 4, pp.308 - 312

Dunphy, D. C., \& Griffiths, A. (1998). The sustainable corporation: organisational renewal in Australia. St Leonards, Australia: Allen \& Unwin.

Eisenhardt, K. M. (1989). Building theories from case study research. Academy of management review, 14(4), 532-550.

Fahey, L., Srivastava,R., Sharon, J.S. and Smith, D.E.(2001). Linking e-business and operating processes: the role of knowledge management. IBM Systems Journal. Vol.40(4), pp.889-908

Farhoomand, A., \& Wigand, R. (2003). Special section on managing e-business transformation. European Journal of Information Systems, 12(4), 249-250.

Fassoula, E.D. (2006). Transforming the supply chain. Journal of Manufacturing Management. Vol. 17(6), pp. 848-860

Flyvbjerg, B. (2006). Five misunderstandings about case-study research. Qualitative inquiry, 12(2), 219-245.

Folkerts H., Koehorst, H. (1998). Challenges in the international food supply chains: vertical cordination in the European agribusiness and food industries. British Food Journal. Vol. 100, No.8, pp.385-388 
Gale, J. and Abraham, D. (2005). "Introduction: toward understanding e-business transformation", Journal of organizational change Management. Vol. 8(2), pp. 113116

Holweg, M., \& Pil, F. K. (2001). Start with the customer. Sloan Management Review.

Howard, M., Vigden, R., and Powell, P. (2003). Overcoming stakeholder barriers in the automotive industry: building to order with extra-organisational systems. Journal of Information Technology,18(27), 43.

Kempainen, K. and Versäläinen (2003). Trends in industrial supply chains and networks. International Journal of Physical Distribution and Logistics Management. Vol.33, No.8, pp.701-719

Markus, M.L. and M. Keil (1994). If We Build it, They Will Come: Designing Information Systems that People Want to Use, Sloan Management Review, 35, 1125

Mirchandani, D. A., \& Lederer, A. L. (2004). IS planning autonomy in US subsidiaries of multinational firms. Information \& management, 41(8), 1021-1036.

Mitki, Y., Shani, A.B., Stjernberg, T. (2008). Leadership, development and learning mechanisms. Leadership and Organization Development Journal. Vol.29(1), pp. $68-84$

Mohdazain, M.R. and Ward, J.M. (2007). A study of subsidiaries' views of information systems strategic planning in multinational organisations, Journal of Strategic Information Systems, Vol.16, pp. 324-352

Mouritson, J., Skjott-Larsen, T. and Kotzab, H. (2003). Exploring the contours of supply chain management. Integrated Manufacturing Systems. Vol. 4, No.8, pp.686-695 
Nyaga, G. N., Whipple, J. M., \& Lynch, D. F. (2010). Examining supply chain relationships: do buyer and supplier perspectives on collaborative relationships differ? Journal of Operations Management, 28(2), 101-114.

Phan, D. D. (2003), "E-business developments for a competitive advantages: a case study", Information and Management, vol. 40, pp. 581-590.

Porras, J. I., \& Silvers, R. C. (1991). Organization development and transformation. Annual review of Psychology, 42(1), 51-78.

Prahalad, C. K., \& Oosterveld, J. P. (1999). Transforming internal governance: the challenge for multinationals. Sloan Management Review, 40, 31-40.

Quayle, M. (2003). A study of supply chain management practice in UK industrial SMEs. Supply Chain Management: An International Journal, 8(1), 79-86.

Rockart, J. F., \& Morton, M. S. (1984). Implications of changes in information technology for corporate strategy. Interfaces, 14(1), 84-95.

Van Donk, D. P. (2007). Challenges in relating supply chain management and information and communication technology. International Journal of Operations and Productions Management, Vol. 28, No.4, pp.308-312

Walker, H. and Harland, C. (2008). E-procurement in the United Nations: influences, issues and impact. International Journal of Operations and Production Management. Vol.28, No.9, pp.831-857

Walton, S.V. Gupta, J.N.D. (1999). Electronic Data interchange for process change in an integrated supply chain. International Journal of Operations and Productions Management, Vol. 19, No.4, pp.372-388

Wiengarten, F.; Humphreys, P.; Cao, G.; Fynes, B. and McKittrick, A. (2010). Collaborative supply chain practices and performance: Exploring the key role of 
information quality. Supply Chain Management: An International Journal 15(6), 463-473.

Taylor, A., \& Taylor, M. (2009). Operations management research: contemporary themes, trends and potential future directions. International Journal of Operations \& Production Management, 29(12), 1316-1340.

Zhu, K. (2004), "The complementarity of information technology infrastructure and e-commerce capability: a resource-based assessment of their business value", Journal of Management Information Systems, Vol. 21 No.1, pp.167-202. 
